\title{
High Power Amplifier (HPA) pada Frekuensi 437,430 MHz untuk Aplikasi TTC Downlink Nano Satelit TEL-U SAT
}

\section{High Power Amplifier (HPA) at 437.430 MHz Frequency for TTC Downlink Application in TEL-U SAT Nano Satellite}

\author{
Y. Taryana ${ }^{\mathrm{a}, *}$, T. Praludi ${ }^{\mathrm{a}}$, Y. Sulaeman ${ }^{\mathrm{a}}$, Y. Wahyu ${ }^{\mathrm{a}}$, \\ W. I. Prayogo ${ }^{b}$, dan B. S. Nugrohob \\ ${ }^{a}$ Pusat Penelitian Elektronika dan Telekomunikasi, Lembaga Ilmu Pengetahuan Indonesia. \\ Komp LIPI Gd 20, Jl. Sangkuriang 21/54D, Bandung 40135, Indonesia \\ ${ }^{b}$ Teknik Telekomunikasi, Fakultas Teknik Elektro, Universitas Telkom. \\ Jalan Telekomunikasi No. 1 Terusan Buah Batu, Bandung 40257, Indonesia
}

\begin{abstract}
Abstrak
Sistem Telemetry, Tracking, and Command (TTC) berfungsi sebagai interface komunikasi antara nano satelit dengan stasiun bumi. Salah satu perangkat yang penting dalam TTC adalah transmitter yang bekerja pada frekuensi downlink 437,430 MHz. Dari perhitungan link budget diperlukan sebuah high power amplifier (HPA) yang memiliki daya output $30 \mathrm{dBm}$ agar data yang dikirimkan dapat diterima dengan baik oleh stasiun bumi. Pada tulisan ini dirancang dan direalisasikan HPA dua tingkat dengan frekuensi kerja 435 - $438 \mathrm{MHz}$. Penguat daya tingkat pertama menggunakan komponen aktif transistor BFR96S dan penguat daya tingkat kedua menggunakan komponen aktif transistor MRF555. Penyepadanan impedansi input menggunakan metode impedance matching Pi-network, sedangkan untuk penyepadanan impedansi interstage dan output menggunakan metode impedance matching T-network. Simulasi penguat daya menggunakan software Advance Design System (ADS 2011). Hasil perancangan HPA pada frekuensi 437,430 MHz menghasilkan gain sebesar 28,400 dB, VSWRin sebesar 1,291, dan VSWRout sebesar 1,295. Dari hasil pengukuran prototipe HPA, pada frekuensi 437,430 MHz menghasilkan gain sebesar 23,01 dB, VSWRin sebesar 2,126, VSWRout sebesar 1,695 pada bandwidth $50 \mathrm{MHz}$.
\end{abstract}

Kata kunci : Nano Satelit, TTC, HPA, gain , matching.

Abstract

Telemetry, Tracking, and Command (TTC) system is functioning for communication between the nanosatellite and earth station. One of the important part in TTC is a transmitter that works at 437,430 MHz downlink frequency. By link budget calculation, it is required a high power amplifier (HPA) which has $30 \mathrm{dBm}$ output power in order to guarantee that transmitted data are still being received by the earth station. This paper presents the design and realization of two stage HPA working in frequency of 435 - $438 \mathrm{MHz}$. The first stage amplifier uses active component BFR96S transistor and for the second stage amplifier, MRF555 transistor is used. Impedance matching input of HPA circuit used Pi-network impedance matching technique, for interstage and output impedance matching used T-network impedance matching technique. In the design and simulation of HPA used Advance Design System (ADS 2011) software. HPA design has characterization results at $437.430 \mathrm{MHz}$ frequency as follow 28,400 dB for gain, 1.291 of VSWRin, 1.295 of VSWRout, and -17.936 of return loss respectively. In the measurement of HPA prototype at $437.430 \mathrm{MHz}$ frequency has characterization results $23.01 \mathrm{~dB}$ for gain, 2.126 of VSWRin, and 1.695 of VSWRout at $50 \mathrm{MHz}$ of bandwidth.

Keywords : Nanosatellite, TTC, HPA, gain, VSWR, impedance matching.

\section{Pendahuluan}

Dewasa ini perkembangan nano satelit sangat pesat. Telkom University bersama Aerospace Exploration Center (AXC) turut berpartisipasi dalam pengembangan teknologi nano satelit di Indonesia. Nano satelit merupakan satelit berukuran kecil $1 \mathrm{U}$ $(10 \mathrm{~cm} \times 10 \mathrm{~cm} \times 10 \mathrm{~cm})$ atau $2 \mathrm{U}(20 \mathrm{~cm} \times 10 \mathrm{~cm} \times 10 \mathrm{~cm})$ dengan massa kurang dari $10 \mathrm{~kg}$ [1]. Nano satelit yang sedang diteliti ini diberi nama Tel-U SAT dengan misi

\footnotetext{
* Corresponding Author.

Email: yanvirs@gmail.com

Received: November 23, 2016; Revised: December 5, 2016

Accepted: December 5, 2016

Published: December 20, 2016

(C) 2016 PPET - LIPI

doi: $10.14203 /$ jet.v16.40-45
}

penginderaan jarak jauh untuk pengawasan wilayah Indonesia. Tel-U SAT dengan ukuran 1U diproyeksikan akan mengorbit di Low Earth Orbit pada ketinggian 700 $\mathrm{km}$ di atas permukaan bumi. Salah satu blok sistem yang terdapat pada nano satelit yakni TTC (Telemetry, Tracking, and Command). Telemetry merupakan pengukuran jarak jauh, tracking berguna untuk mengetahui letak (posisi) satelit, dan command berguna untuk mengirim perintah ke satelit [2].

Salah satu modul yang mempunyai fungsi penting adalah penguat daya. Penguat daya berfungsi untuk meningkatkan level daya sinyal sebelum dipancarkan melalui antena. Pada tulisan ini dirancang dan direalisasikan high power amplifier (HPA) dua tingkat untuk aplikasi TTC downlink yang dapat bekerja pada frekuensi 437,430 $\mathrm{MHz}$ dengan bandwidth $30 \mathrm{KHz}$. 
Spesifikasi dari HPA yang dirancang yakni memiliki gain $30 \mathrm{~dB}, 1 \leq \mathrm{VSWR} \leq 1,5$, return loss $\leq$ $15 \mathrm{~dB}$, amplifier kelas A.

\section{TELEMETRY, TrACKING, AND COMMAND}

Gambar 1 menjelaskan sistem TTC berfungsi sebagai interface komunikasi antara satelit dengan stasiun bumi. Sistem tersebut bertugas untuk mengirim data telemetri dari satelit ke stasiun bumi, menerima perintah (command) yang dikirim dari stasiun bumi, dan mengirim sinyal tracking (lokasi dan posisi satelit) ke stasiun bumi [3][4]. TTC downlink nano satelit yang dirancang menggunakan standar frekuensi yang telah disediakan oleh ORARI (Organisasi Radio Amatir Republik Indonesia), yakni bekerja pada frekuensi UHF 437,430 MHz dengan bandwidth $30 \mathrm{KHz}$.

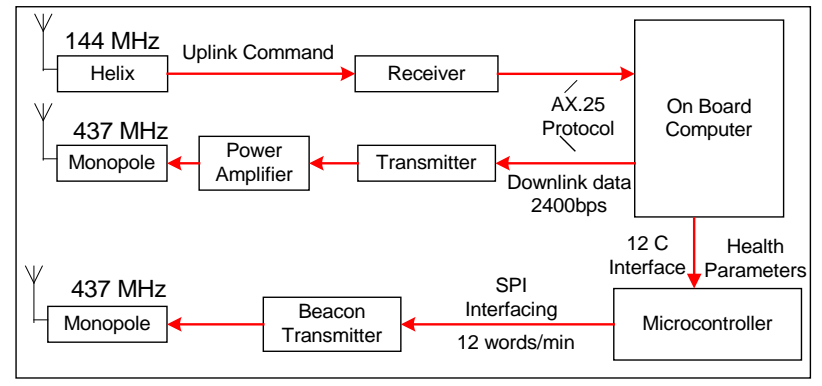

Gambar 1. Blok Diagram Sistem TTC [4]

\section{A. High Power Amplifier (HPA)}

Power Amplifier berfungsi untuk meningkatkan level daya sinyal pada masukan di rentang frekuensi yang telah ditentukan sampai dengan level daya yang diinginkan pada keluarannya [5]. Kemampuan dari suatu power amplifier tergantung dari karakteristik komponen aktif yang digunakan. Pada tulisan ini, HPA dirancang dengan dua tingkat untuk mencapai penguatan atau gain $\geq 20 \mathrm{~dB}$. Pada tingkat pertama menggunakan transistor BJT BFR96S sebagai driver amplifier dan pada tingkat ke 2, menggunakan transistor BJT MRF555 sebagai transistor akhir yang memiliki karakteristik dapat bekerja hingga frekuensi $470 \mathrm{MHz}$ dengan daya keluaran 1,5 Watt [6],[7]. Pada Gambar 2, HPA dirancang menggunakan teknik simultaneous conjugate match untuk mendapatkan penguatan yang maksimal. Dalam teknik ini, rangkaian harus memenuhi kondisi:

$\Gamma_{\mathrm{S} 1}=\Gamma_{\text {in } 1}{ }^{*}, \Gamma_{\text {out } 1}=\Gamma_{\mathrm{L} 1}{ }^{*}, \Gamma_{\mathrm{S} 2}=\Gamma_{\text {in } 2}{ }^{*}$ dan $\Gamma_{\text {out } 2}=\Gamma_{\mathrm{L} 2}{ }^{*}[8]$.

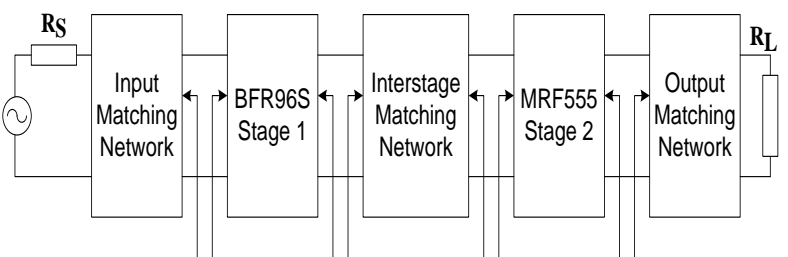

$\Gamma_{\mathrm{S} 1} \Gamma_{\text {in1 }} \quad \Gamma_{\text {out1 }} \Gamma_{\mathrm{L} 1} \quad \Gamma_{\mathrm{S} 2} \Gamma_{\text {in2 } 2} \Gamma_{\text {out2 } 2} \Gamma_{\mathrm{L} 2}$

Gambar 1. HPA Dua Tingkat dengan Simultaneous Conjugate Match.

Dengan

$$
\Gamma_{i n}=S_{11}+\frac{S_{12} S_{21} \Gamma_{L}}{1-S_{22} \Gamma_{L}}
$$

$$
\Gamma_{\text {out }}=S_{22}+\frac{S_{12} S_{21} \Gamma_{S}}{1-S_{11} \Gamma_{S}}
$$

\section{B. DC Biasing}

Direct Current (DC) Biasing atau rangkaian prategangan DC digunakan untuk mengaktifkan transistor BJT agar dapat bekerja pada titik kerja (Q) yang diinginkan. Konfigurasi DC biasing yang digunakan adalah jenis self-bias seperti yang ditunjukkan pada Gambar 3 [10].

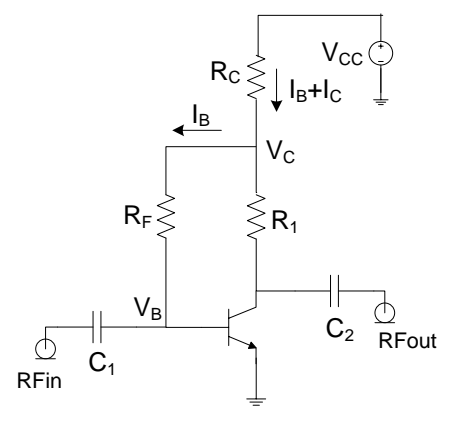

Gambar 3. Rangkaian DC Biasing.

\section{Stabilitas Penguat Daya}

Dalam perancangan penguat daya, faktor kestabilan (K) mempunya peranan penting agar sebuah penguat tidak terjadi osilasi. Secara matematis K dapat dihitung melalui Persamaan (3) dan (4) [8].

$$
\begin{aligned}
& K=\frac{1-\left|S_{11}\right|^{2}-\left|S_{22}\right|^{2}+|\Delta|^{2}}{2\left|S_{12} S_{21}\right|} \\
& \Delta=S_{11} S_{22}-S_{12} S_{21}
\end{aligned}
$$

Jika $\mathrm{K}>1$ dan $\Delta<1$, transistor memiliki kestabilan tanpa syarat (unconditionally stable) untuk semua impedansi sumber dan beban. Pada kondisi ini transistor cocok digunakan sebagai penguat.

\section{Penentuan Parameter S dan Faktor Kestabilan}

Dengan menggunakan tools $S$-parameters pada perangkat lunak ADS 2011, pada frekuensi 437,430 $\mathrm{MHz}$ diperoleh nilai parameter $\mathrm{S}$ untuk rangkaian BFR96S dan MRF555 sebagai berikut: Parameter S transistor BFR96S pada $437,430 \mathrm{MHz}$ adalah $\mathrm{S}_{11}=$ $0,350 \angle 165,660^{\circ}, \mathrm{S}_{12}=0,085 \angle 70,601^{\circ}, \mathrm{S}_{21}=4,792 \angle$ $79,389^{\circ}$ dan $\mathrm{S}_{22}=0,107<-69,726^{\circ}$ sedangkan parameter $\mathrm{S}$ transistor MRF555 pada $437,430 \mathrm{MHz}$ adalah $\mathrm{S}_{11}=0,785 \angle 171,670^{\circ}, \mathrm{S}_{12}=0.047 \angle 57,619^{\circ}$, $\mathrm{S}_{21}=2,614 \angle 77,819^{\circ}$ dan $\mathrm{S}_{22}=0.584 \angle 179,792^{\circ}$.

Dengan menggunakan Persamaan 3 dan 4 maka diperoleh nilai-nilai untuk transistor BFR96S dengan $|\Delta|=0,386$ dan $K=1,247$. Sedangkan untuk transistor MRF555 diperoleh nilai $|\Delta|=0,562$ dan $\mathrm{K}=1,461$.

\section{E. Penyepadanan Impedansi}

Apabila impedansi sebuah saluran tidak match dengan saluran lain yang terhubung padanya, maka akan menimbulkan rugi-rugi seperti adanya daya yang memantul sehingga menyebabkan transfer daya tidak maksimum. Teknik penyepadanan impedansi yang 
dapat digunakan untuk band frekuensi UHF yakni $\mathrm{Pi}$ network dan T-network seperti yang ditunjukan pada Gambar 4 dan 5.

Dalam melakukan penyepadanan impedansi harus diketahui terlebih dahulu nilai dari $Z_{S}$ dan $Z_{L}$ yang akan disepadankan. Dengan menggunakan Persamaan 1 dan 2, kondisi simultaneous conjugate match maka diperoleh nilai $\Gamma_{S}$ dan $\Gamma_{L}$ untuk transistor tingkat pertama (BFR96S), yaitu $\Gamma_{S 1}=0,476 \angle-171,052^{\circ}$ dan $\Gamma_{L 1}=0,316 \angle 37,015^{\circ}$, sedangkan transistor tingkat kedua diperoleh nilai $\Gamma_{S 2}=0,755 \angle-176,888^{\circ}$ dan $\Gamma_{L 2}=0,468 \angle 158,971^{\circ}$. Nilai-nilai koefesien refleksi ( $\Gamma$ ) harus dikonversi ke nilai impedansi (Z) untuk mempermudah dalam menghitung rangkaian penyepadan impedansi, yaitu dengan Persamaan 3 dan 4 [8].

$$
\begin{aligned}
& Z_{S}=Z_{O} \frac{1+\Gamma_{S}}{1-\Gamma_{S}} \\
& Z_{L}=Z_{O} \frac{1+\Gamma_{L}}{1-\Gamma_{L}}
\end{aligned}
$$

sehingga dari Persamaan 3 dan 4 diperoleh nilai-nilai untuk $Z_{\mathrm{S} 1}=18,066-\mathrm{j} 3,456, Z_{\mathrm{L} 1}=75,304+\mathrm{j} 30,888$, $Z_{\mathrm{S} 2}=7,017-\mathrm{j} 1,313$, dan $Z_{\mathrm{L} 2}=18,561+\mathrm{j} 7,896$.

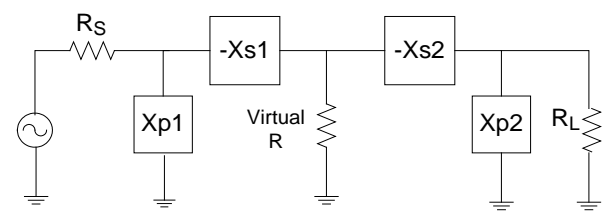

Gambar 4. Pi-Network

Pada Gambar 4, nilai-nilai komponen Xs dan Xp dapat diperoleh melalui Persamaan 7-12 [9].

$$
\begin{aligned}
& R=\frac{R_{H}}{Q^{2}+1} \\
& X_{P 2}=\frac{R_{L}}{Q} \\
& X_{S 2}=Q R_{\text {series }} \\
& Q_{1}=\sqrt{\frac{R_{S}}{R}-1} \\
& X_{p 1}=\frac{R_{p}}{Q_{1}} \\
& X_{S 1}=Q_{1} R_{\text {series }}
\end{aligned}
$$

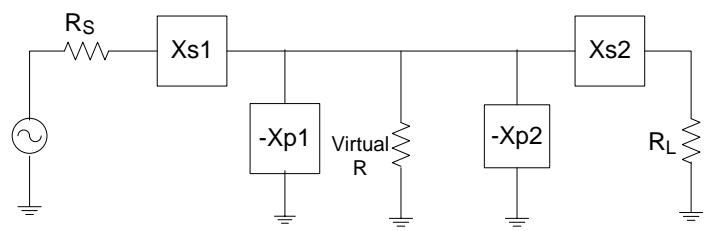

Gambar 5. T- Network
Sedangkan pada Gambar 5 untuk menentukan nilainilai Xs dan Xp melalui Persamaan 13-18 [9].

$$
\begin{aligned}
& R=R_{S}\left(Q^{2}+1\right) \\
& X_{S 1}=Q R_{S} \\
& X_{P 1}=\frac{R}{Q} \\
& Q_{2}=\sqrt{\frac{R}{R_{L}}-1} \\
& X_{P 2}=\frac{R}{Q_{2}} \\
& X_{S}=Q_{2} R_{L}
\end{aligned}
$$

\section{F. Penyepadanan Impedansi Input}

Penyepadanan impedansi input dilakukan dengan menyepadankan $Z_{\mathrm{S} 1}$ dengan $50 \mathrm{O}$ hm. Teknik penyepadanan impedansi yang digunakan yakni PiNetwork Impedance Matching seperti Gambar 4 dengan menggunakan nilai $\mathrm{Q}$ minimum dan memasukkan nilai $\mathrm{R}_{\mathrm{H}}=\mathrm{R}_{\mathrm{L}}=50 \mathrm{Ohm}, \mathrm{R}_{\mathrm{S}}=\mathrm{R}_{\mathrm{P}}=18,066 \mathrm{Ohm}$ dan $\mathrm{Q}=2$ pada Persamaan 7-12 maka diperoleh nilai $\mathrm{X}_{\mathrm{P} 2}=25$ Ohm, $\mathrm{X}_{\mathrm{S} 2}=20$ Ohm, $\mathrm{X}_{\mathrm{P} 1}=20,12 \mathrm{Ohm}$, dan $\mathrm{X}_{\mathrm{S} 1}=8,98$ Ohm sehingga rangkaian menjadi seperti yang ditunjukkan oleh Gambar 6.

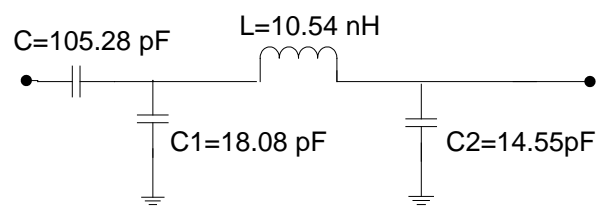

Gambar 6. Rangkaian Penyepadanan Impedansi Input

\section{G. Penyepadanan Impedansi Interstage}

Penyepadanan impedansi interstage dilakukan dengan menyepadankan $Z_{\mathrm{S} 2}$ terhadap $Z_{\mathrm{L} 1}$. Teknik penyepadanan impedansi yang digunakan yakni $T$ Network Impedance Matching seperti pada Gambar 5 dengan memasukkan nilai $\mathrm{Rs}=7,017 \mathrm{ohm}, \mathrm{R}_{\mathrm{L}}=75,304$ ohm dan $\mathrm{Q}=3,5$ pada Persamaan 13-18, maka diperoleh nilai $\mathrm{X}_{\mathrm{S} 1}=21,40 \mathrm{Ohm}, \mathrm{X}_{\mathrm{P} 1}=26,57 \mathrm{Ohm}, \mathrm{X}_{\mathrm{P} 2}$ $=193,71 \mathrm{ohm}$, dan $\mathrm{X}_{\mathrm{S} 2}=36,14 \mathrm{ohm}$ sehingga rangkaian menjadi seperti yang ditunjukan oleh Gambar 6 .

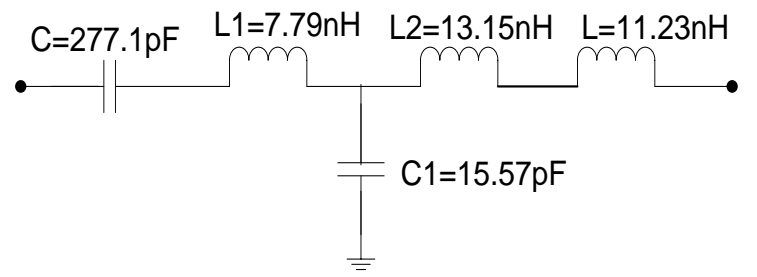

Gambar 7. Rangkaian Penyepadanan Impedansi Interstage

\section{H. Penyepadanan Impedansi Output}

Penyepadanan impedansi output dilakukan dengan menyepadankan $Z_{\mathrm{L} 2}$ dengan $50 \mathrm{O}$ hm. Teknik penyepadanan impedansi yang digunakan yakni $T$ - 
Network Impedance Matching seperti Gambar 5. Dengan cara yang sama dengan penyepadan impedansi interstage dan dengan memasukkan nilai $\mathrm{Rs}=18,561$ ohm, $\mathrm{R}_{\mathrm{L}}=50 \mathrm{Ohm}$ dan $\mathrm{Q}=1$, maka diperoleh nilai $\mathrm{X}_{\mathrm{S} 1}$ $=27,84 \mathrm{Ohm}, \mathrm{X}_{\mathrm{P} 1}=40,21 \mathrm{Ohm}, \mathrm{X}_{\mathrm{P} 2}=134,04 \mathrm{Ohm}$, dan $\mathrm{X}_{\mathrm{S} 2}=22,5 \mathrm{Ohm}$ dan rangkaian pengganti ditunjukan oleh Gambar 8.

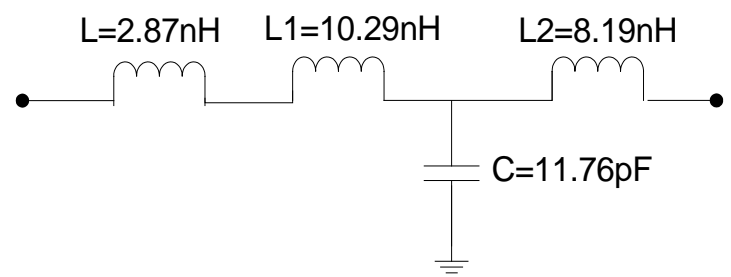

Gambar 8. Rangkaian Penyepadanan Impedansi Output

III. SIMULASI RANGKAIAN HPA

Proses akhir perancangan menghasilkan rangkaian lengkap HPA seperti yang ditunjukan pada Gambar 9 . Rangkaian tersebut dilengkapi dengan $R F$ choke dan $D C$ blocking. RF choke ditunjukkan oleh komponen L5, L6, L7, dan L8. Sedangkan DC blocking ditunjukkan oleh DC block1 dan DC block2.

Proses selanjutnya adalah mensimulasikannya dengan menggunakan perangkat lunak ADS 2011. Tujuan simulasi untuk mendapatkan karakterisasi hasil perancangan sebelum rangkaian direalisasikan. Proses ini memberikan hasil gain, VSWRin, dan VSWRout.

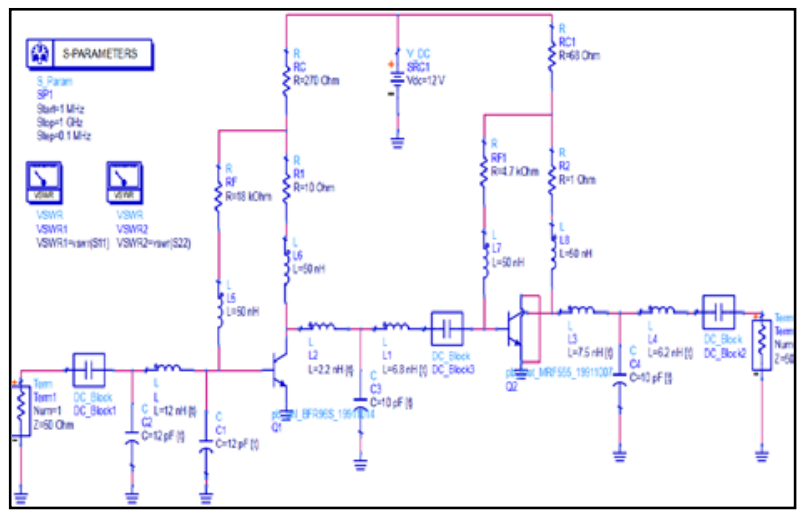

Gambar 9. Rangkaian Akhir HPA Dua Tingkat

Dari hasil simulasi pada frekuensi 437,430 MHz, HPA memiliki gain $=28,400 \mathrm{~dB}$, VSWRin $=1,291$ dan VSWRout $=1,295$.

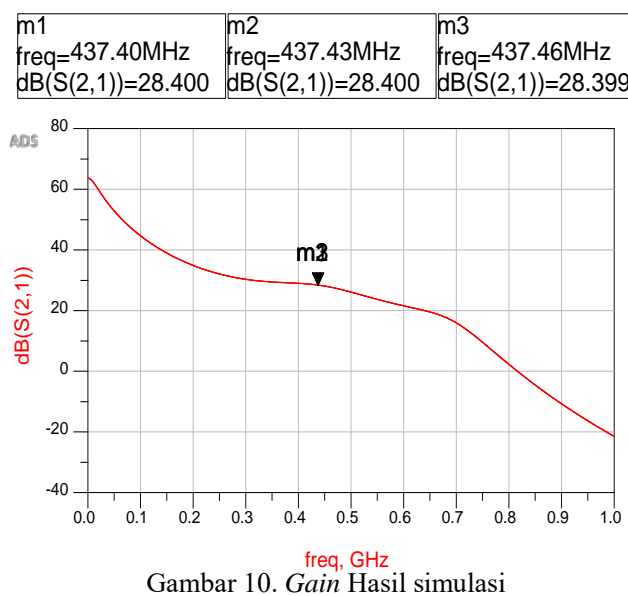

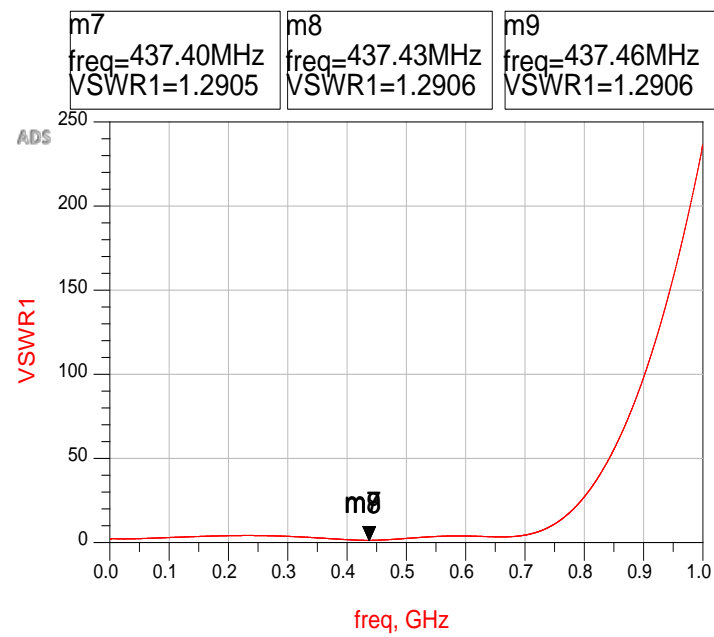

Gambar 11. VSWRin Hasil Simulasi

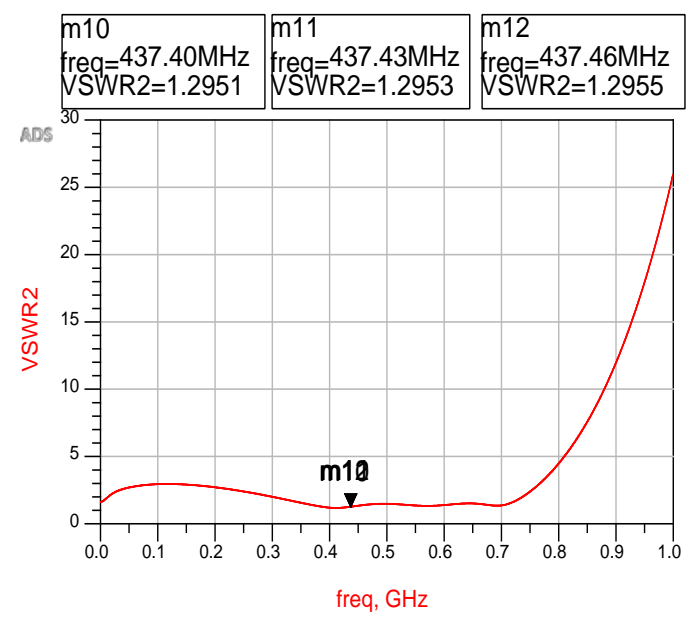

Gambar 12 . VSWRout Hasil Simulasi

Dari hasil keseluruhan simulasi menunjukkan hasil yang sesuai dengan spesifikasi kebutuhan HPA untuk nano satelit. Proses selanjutnya adalah merealisasikannya menjadi sebuah prototipe seperti yang ditunjukkan pada Gambar 13 dan 14

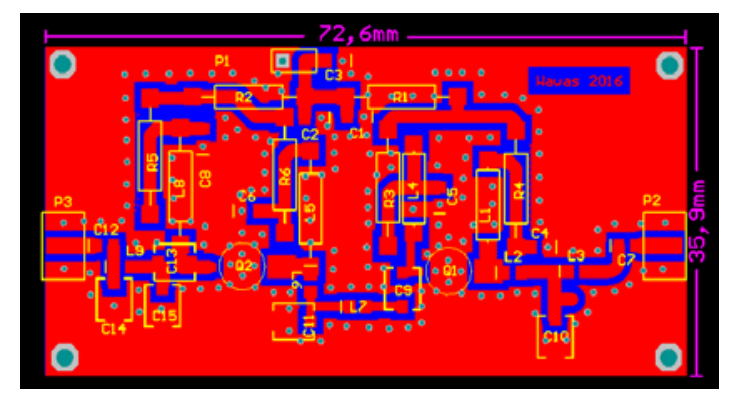

Gambar 13. Desain PCB Rangkaian HPA

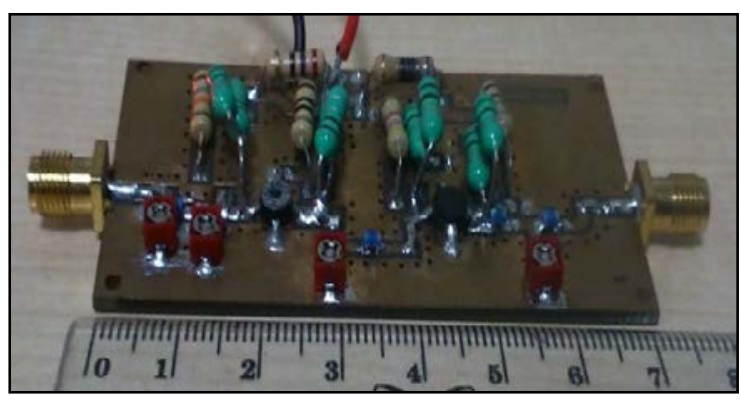

Gambar 14. Prototipe HPA 


\section{PENGUKuRAN dAN ANALISIS}

\section{a) Pengukuran Gain}

Pengukuran gain dilakukan pada rentang frekuensi $300 \mathrm{MHz}$ sampai $500 \mathrm{M} \mathrm{Hz}$ dengan memberikan masukkan level daya sebesar $0 \mathrm{dbm}$, redaman terminasi $30 \mathrm{~dB}$ dan redaman kabel sebesar $1 \mathrm{~dB}$ dan hasilnya ditunjukkan pada Tabel 1. Pada frekuensi 437,440 MHz dan pada bandwidth TTC $(437,40-437,46 \mathrm{MHz})$ menghasilkan gain sebesar sebesar 23,01 dB.

Terjadi perbedaan nilai gain antara simulai dan pengukuran realisasi HPA, hal ini dikarenakan pada simulasi menggunakan perangkat lunak ADS komponen-komponen yang digunakan yakni komponen ideal yang mempunyai faktor kualitas sangat tinggi, sedangkan pada realisasi HPA menggunakan komponen-komponen dengan faktor kualitas tertentu sehingga terjadi perbedaan nilai komponen antara simulasi dengan realisasi. Pada saat memutar nilai kapasitor trimmer, apabila nilainya tidak sama tepat dengan nilai pada saat simulasi maka gain yang dihasilkan tidak maksimal.

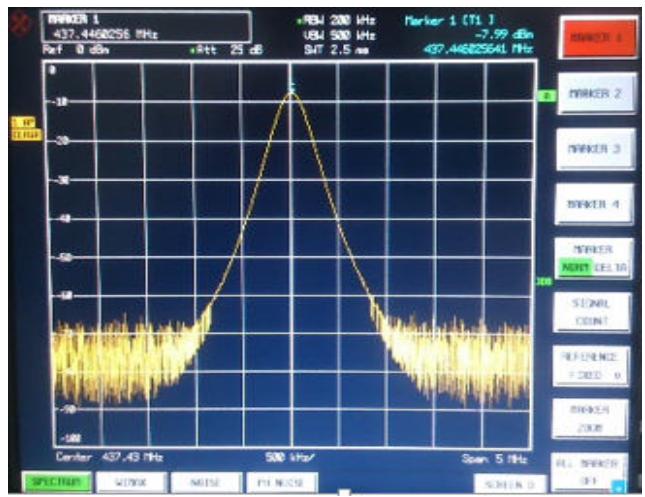

Gambar 15. Hasil Pengukuran Gain pada Frekuensi 437,44 MHz

TABEL 1

HaSil PENGUKURAN GAIN RANGKAIAN HPA

\begin{tabular}{|l|l|l|l|}
\hline \multicolumn{1}{|c|}{ F(MHz) } & Pin(dBm) & Pout $(\mathbf{d B m})$ & Gain $(\mathbf{d B})$ \\
\hline 300 & 0 & $-8,30$ & 22,70 \\
\hline 350 & 0 & $-11,03$ & 19,97 \\
\hline 400 & 0 & $-8,24$ & 22,76 \\
\hline 435 & 0 & $-7,98$ & 23,02 \\
\hline 437,43 & 0 & $-7,99$ & 23,01 \\
\hline 438 & 0 & $-8,00$ & 23,00 \\
\hline 450 & 0 & $-8,39$ & 22,61 \\
\hline 500 & 0 & $-13,91$ & 17,09 \\
\hline
\end{tabular}

\section{b) Pengukuran VSWR}

Pengukuran VSWR menggunakan vector network analyzer dan dicatu dengan DC power supply $12 \mathrm{~V}$. Pada frekuensi $437,430 \mathrm{MHz}$ menghasilkan VSWR input sebesar 2,126 dan VSWR output sebesar 1,695 seperti ditunjukkan pada Gambar 16 da n 17. Apabila dibandingkan dengan spesifikasi awal hasil simulasi, maka hasil pengukuran memiliki nilai VSWR $>1,5$. Hal ini diakibatkan oleh rangkaian HPA yang tidak match, dikarenakan komponen-komponen yang digunakan pada realisasi memiliki faktor kualitas tertentu di mana terjadi sedikit perbedaan nilai-nilai komponen $D C$ biasing dan titik kerja transistor antara simulasi dengan direalisasikan, sehingga faktor-faktor tersebut dapat mempengaruhi nilai scattering parameters yang digunakan dalam menentukan koefisien pantul dan juga penyepadanan impedansi.

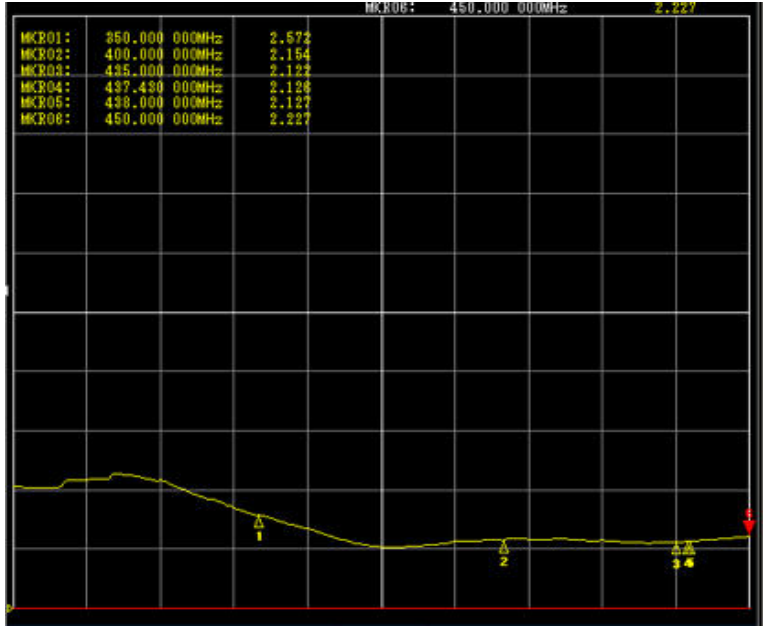

Gambar 16. Hasil Pengukuran VSWR Input

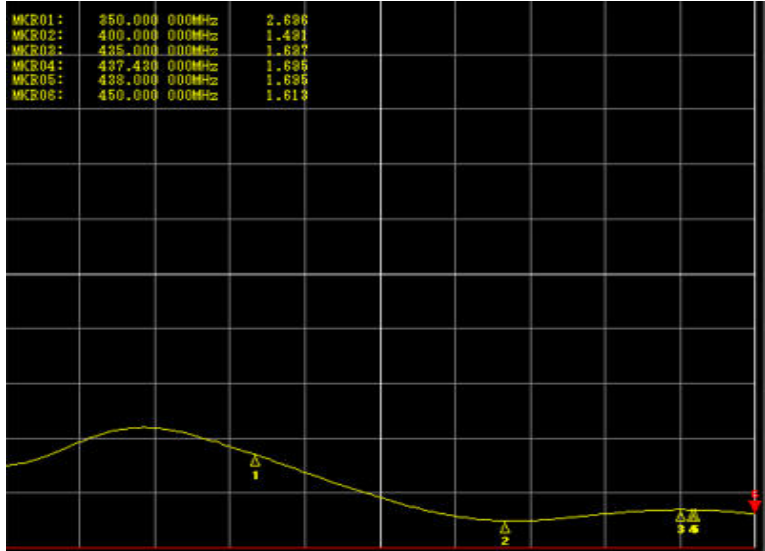

Gambar 17. Hasil Pengukuran VSWR Output

\section{KESIMPULAN}

Proses perancangan dan realisasi HPA pada frekuensi 437,430 MHz untuk aplikasi TTC downlink nano satelit telah disimulasikan, dibuat prototipe dan dilakukan pengukuran. Dari hasil pengukuran, pada frekuensi 437,430 $\mathrm{MHz}$ menghasilkan gain sebesar 23,01 dB, VSWRin sebesar 2,126, dan VSWRout sebesar 1,695. Nilai-nilai tersebut tidak memenuhi spesifikasi awal perancangan HPA namun telah mendekati (gain $30 \mathrm{~dB}$, dan $1 \leq \mathrm{VSWR} \leq 1,5$ ). Secara keseluruhan, prototipe HPA ini dapat bekerja pada range bandwidth TTC pada frekuensi 437,40 - 437,46 $\mathrm{MHz}$. Dengan adanya perbedaan ini dapat dilakukan desain ulang untuk mendapatkan nilai yang optimum dengan menggunakan komponen-komponen aktif dengan spesifikasi yang lebih baik.

\section{UCAPAN TERIMA KASIH}

Penulis mengucapkan terima kasih yang sebesarnya kepada PPET - LIPI yang telah mendanai kegiatan DIPA penelitian ini pada tahun anggaran 2016. 


\section{DAFTAR PUSTAKA}

[1] Riki Munakata et all, "CubeSat Design Specifications Rev12," California Polytechnic State University, 2009.

[2] Anil K. Maini and Varsha Agrawal, Satellite Technology Principles and Applications $2^{\text {nd }}$ ed., United Kingdom: John Wiley \& Sons, Inc, 2011

[3] Johan L. Tresvig et all, "CubeSTAR - A Nanosatellite for Space Weather Monitoring," Depatement of Physics, University of Oslo.

[4] Lakshya Vaibhav Datta, Introduction to Nanosatellite Technology and Components, Germany: LAP LAMBERT Academic Publishing, 2012.
[5] Paolo Colantino and Ernesto Franco, High Efficiency RF and Microwave Solid State Power Amplifier, United Kingdom: John Wiley and Sons, Ltd., 2009.

[6] "Data-sheet BFR96S. NPN 5 GHz wideband Transistor," Philips Semiconductor.

[7] "Data-sheet MRF555. The RF Line NPN Silicon RF Low Power Transistor," Motorola Inc.

[8] Guillermo Gonzalez, Microwave Transistor Amplifiers Analysis and Design, New Jersey: Prentice-Hall, Inc, 1997.

[9] Chris Bowick, John Blyler and Cheryl Ajluni, RF Circui Design. 2nd ed., USA: Butterworth-Heinemann, 2008.

[10] Herman Dwi Surjono, Elektronika Analog, Indonesia: Cerdas Ulet Kreatif, 2008 